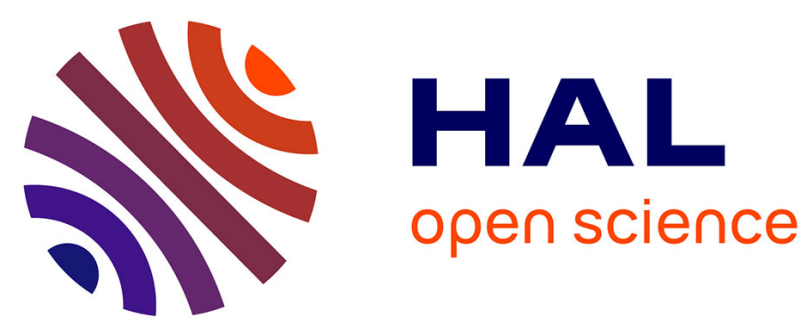

\title{
Modeling intervertebral articulation: The rotule à doigt mechanical joint (RAD) in birds and mammals
}

\author{
Anick Abourachid, Benoît Gagnier, Matthieu Furet, Raphael Cornette, \\ Arnaud Delapre, Remi Hackert, Philippe Wenger
}

\section{To cite this version:}

Anick Abourachid, Benoît Gagnier, Matthieu Furet, Raphael Cornette, Arnaud Delapre, et al.. Modeling intervertebral articulation: The rotule à doigt mechanical joint (RAD) in birds and mammals. Journal of Anatomy, 2021, 239 (6), pp.1287-1299. 10.1111/joa.13517 . mnhn-03445533

\section{HAL Id: mnhn-03445533}

\section{https://hal-mnhn.archives-ouvertes.fr/mnhn-03445533}

Submitted on 24 Nov 2021

HAL is a multi-disciplinary open access archive for the deposit and dissemination of scientific research documents, whether they are published or not. The documents may come from teaching and research institutions in France or abroad, or from public or private research centers.
L'archive ouverte pluridisciplinaire HAL, est destinée au dépôt et à la diffusion de documents scientifiques de niveau recherche, publiés ou non, émanant des établissements d'enseignement et de recherche français ou étrangers, des laboratoires publics ou privés. 
Abourachid, A., Gagnier, B., Furet, M., Cornette, R., Delapre, A., Hackert, R. et al. (2021) Modeling intervertebral articulation: The rotule à doigt mechanical joint (RAD) in birds and mammals. Journal of Anatomy, 00, 1-13. https://doi.org/10.1111/joa.13517

\title{
Modeling intervertebral articulation: the rotule à doigt mechanical joint (RAD) in birds and mammals
}

Anick Abourachid ${ }^{1}$, Benoît Gagnier ${ }^{1}$, Matthieu Furet ${ }^{2}$, Raphael Cornette ${ }^{3}$, Arnaud Delapre ${ }^{3}$, Remi Hackert ${ }^{1}$, Philippe Wenger ${ }^{2}$

1 Mécanismes adaptatifs et Evolution (Mecadev) Museum National d'Histoire Naturelle, CNRS 57, Sorbonne Université, 57 rue Cuvier 75231 Paris cedex 05, France,

2 LS2N-ECN, 1 rue de la Noë, BP 92101, 44321 Nantes cedex 3 France

3 Institut de Systématique, Evolution, Biodiversité (ISYEB) - UMR 7205, Muséum national d'Histoire naturelle, CNRS, Sorbonne Université, EPHE, Université des Antilles, CP 50, 57 rue Cuvier, 75005 Paris, France

Corresponding author: Anick.Abourachid@mnhn.fr

Key words: vertebrae, bird, intervertebral joint, mammal, human

\begin{abstract}
The vertebrate skeleton is composed of articulated bones. Most of the articulations are classically described using mechanical joints, except the intervertebral joint. The aim of this study was to identify a joint model with the same mechanical features as the cervical joints. On the neck vertebrae, six articular surfaces participate in the joint: the cranial part of the centrum and the facets of the two prezygapophyses of a vertebra articulate on the caudal part of the centrum and the two articular facets of the postzygapophyses of the previous vertebra. We used the intervertebral joints of the bird neck to identify the mechanical joint representing intervertebral linkage. This link was described in the literature as a joint allowing two or three rotations and no translation. These features correspond to the rotule à doigt (RAD) joint, a ball and socket joint with a pin. We compared the RAD joint to the postaxial intervertebral joints of the avian neck and found it a suitable model to determine the geometrical features involved in the joint mobility. The difference in the angles of virtual axes linking the geometrical center of the centrum to the zygapophysis surfaces determines the mean dorsoventral flexion of the joint. It also helps to limit longitudinal rotation. The orientation of the zygapophysis surfaces determines the range of motion in both dorsoventral and lateral flexion. The overall system prevents dislocation. The model was validated on 13 joints of a vulture neck and 11 joints of a swallow neck and on one joint (C6-C7) in each of three mammal species: the wolf (Canis lupus), mole (Talpa europaea) and human (Homo sapiens). The RAD mechanical joint was found in all vertebral articulations. This validation of the model on different species shows that the RAD intervertebral joint model makes it possible to extract the parameters that guide and limit mobility of the cervical spine from the complex shape of the vertebrae and to compare them in interspecific studies.
\end{abstract}




\section{Introduction}

The vertebrate skeleton is composed of bones articulated by a diversity of joints. Their mobilities are described schematically using mechanical joints such as a ball and socket joint for the hip, a saddle joint between the carpal and metacarpal bones, and a planar joint between the tarsal bones. Among the skeleton articulations, the intervertebral joint is complex, and no schematic joint has been proposed to extract the geometrical features involved in its mobility. We used the necks of birds as a case study to find a mechanical link that schematically describes the intervertebral joint. The basic functions of the vertebral column are to protect the spinal cord, ensure the passage of nerve and blood networks and anchor the musculature. In amniotes, the head rotates primarily on two anterior cervical vertebrae the atlas and axis $(C 1, C 2)$, which have special shapes. The next vertebrae comprise the following morphological structures (Fig 1): a ventral vertebral body, the centrum, is the basic part of the vertebra. Over the centrum, the paired neural arches form the walls of the neural canal which protects the spinal cord and fuse dorsally into the neural spine, a dorsal process which extends on the top of the vertebra, for muscular attachment. Paired transverse processes project laterally from the base of the arches as rib attachments. Paired zygapophyses extend between successive neural arches, preventing undue torsion. The surface of the anterior zygapophyses, i.e. the prezygapophyses, generally face upward and inward. They are opposed to the downward and outward surfaces of the posterior postzygapophyses of the previous vertebrae (Romer and Parson 1977). In amniotes, the vertebral column may be divided into different regions: caudal, sacral, dorsal and cervical regions. The caudal region is rather free, in terms of number of vertebrae (Müller et al. 2010), and is used in many functions from locomotion to weaponization, social behavior, etc. The sacral region anchors the

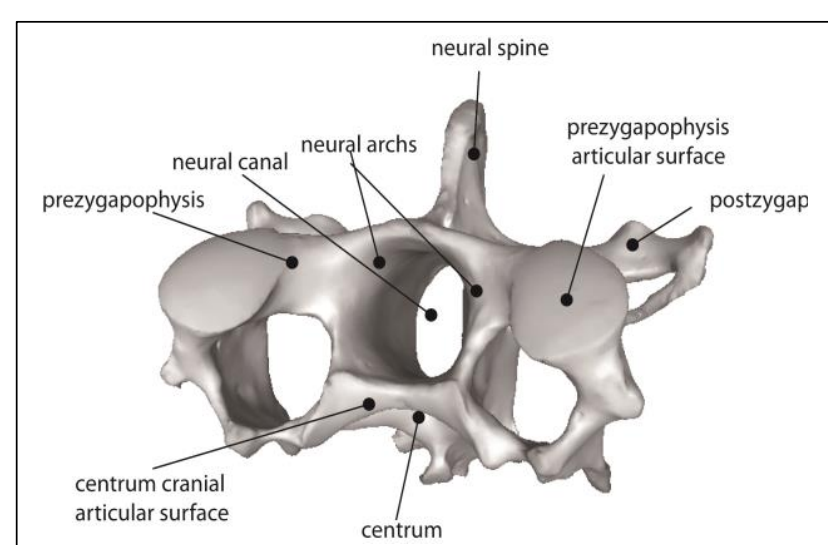

Figure 1 : Bird cervical vertebrae: 4th vertebrae of a vulture (Gyps fulvus) pelvis on the vertebral column; the dorsal region, divided into lumbar and thoracic regions in mammals, supports the trunk. The number of presacral vertebrae and cervical vertebrae varies depending on phylogeny and functional demand (Müller et al. 2010). In current amniotes, the extremes are found in limbless species (110 presacral vertebrae with 6 cervical vertebrae in Dibamidae, limbless lizards (Müller et al. 2010)) and in birds. In mammals, the cervical region almost always comprises 7 cervical vertebrae (Kardong 2012). The cervical region ensures the mobility of the head relative to the trunk. The cervical column of birds is a long series comprising 10 and 26 vertebrae, depending on the species (Boas 1929). It articulates on the thoracic vertebrae on which true ribs articulate. Avian thoracic vertebrae are often ankylosed and merged into a notarium. There is no intervertebral disc between the avian vertebrae (Taylor and Wedel 2013, Böhmer et al. 2019). The first two vertebrae, the atlas and the axis have particular shapes. They do not have prezygapophyses and the atlas has no postzygapophyses either (Boas 1929). These two vertebrae form the craniocervical hinge. Because of their particular shapes and function, we will not study them in this work.

From the intervertebral joint, only the function of the centra has been described schematically, depending on its curvature. It is a ball and socket joint when a concave socket fits with a convex socket, as in most tetrapod cases, or a saddle joint in birds' cervical column (Kardong 2012). However, intervertebral mobility depends not only on the centra joint but also on all articular 
surfaces, the centra and the zygapophyses, which participate in its mechanical properties.

The bird neck is long and flexible, and its vertebrae are very different in terms of number and shape depending on the species (Boas 1929). We use it as a case study to identify the mechanical joint because of this variability. We hypothesize that if we found a mechanical model that fits the cervical vertebrae of the birds, it may fit those of other vertebrates as well.

The shape of the cervical vertebrae of birds is complex. There is no disc between the centra, but a thin cartilage covers the articular facets (Taylor and Wedel 2013, Böhmer et al. 2020). All the vertebrae are different and only fit perfectly with the neighboring vertebrae in the cervical column, to such an extent that it is possible to determine without error the order of their succession, from the atlas to the thoracic vertebrae, from an individual's isolated vertebrae. The cervical column is also different between the species. The number of cervical vertebrae is globally related to phylogeny, and older groups, such as ratites, have more vertebrae than more recent groups, such as psittacids (Böhmer et al. 2019). However, within phylogenetically close taxa, the number may vary. They look like they are more related to functional constraints, as in vultures (Böhmer et al. 2020). Böhmer et al. showed that while the length of the neck generally varies isometrically with the size of a bird, some species have a longer neck than expected. Similarly, while generally a long neck has long vertebrae, the long neck of the swan is formed by many short vertebrae, whereas the long neck of the pink flamingo is formed by a series of long vertebrae (Böhmer et al. 2019).

Regardless of neck length, there are at least three areas in the bird neck, giving it a typical S shape (Boas 1929). The cranial area is mainly ventroflexed, the intermediate area is mainly dorsoflexed, and the prethoracic area is mainly straight (Bout 1997, Van der Leeuw et al 2001, Krings et al 2014, Kambic 2017). In those series of vertebrae, it is possible to recognize trans-specific patterns. By analyzing the shapes of the 107 vertebrae from 17 species via an without a priori analysis, i.e. clustering the vertebra shapes without qualitative information, Terray et al. (2020) using 3D geometric morphometrics identified nine trans-specific modules, which cluster vertebrae of several species. The clustered vertebrae correspond to comparable topological distributions in the spine of the birds (i.e. cranial, intermediate and prethoracic). Module 1 is the most widely shared by the species studied (14/15 species) and corresponds to the vertebrae just after the axis, the cranial part of the neck. Module 9 is found in the same part, but is rare, found in one species of the sample. Module 2 is shared by 9 species out of 15, and corresponds to the middle part of the neck. Module 5 is also found in the middle of the neck, in 5 species out of 15 . Module 6 is shared by 11 species out of 15 , and corresponds to the prethoracic part of the neck. Modules 3, 7 and 9 are also found in this last neck region, but are rarer. A 3D geometric morphometric analysis was performed to calculate the mean shape and create a 3D mean vertebra for each module. These modules mean that vertebrae share shape characteristics common to several species (Terray et al. 2020). When articulated together, the series of mean vertebrae in a module showed the articular orientation typical of the topological flexibility. For instance, the association of four mean vertebrae in the module 2 found in the middle of the neck forms a dorso flexed series typical of this region.

The main characteristic of the bird neck is that many vertebrae, with many joints, allow head mobility toward the trunk (Van der Leeuw et al 2001, Cobley et al 2013). Krings (2017) examined in detail the intervertebral mobility of the owl and observed that the high flexibility of the cervical column results from the complex combination of lateral and dorsoventral movements, with two rotations, at the level of each joint. For instance, lateral movements were allowed only when the joint was ventro-flexed. Kambic et al. (2017) observed the same in guinea fowl, showing that the complex rotation movements were related to zygapophysis orientation. They also observed a small longitudinal rotation between the 3-4 and 4-5 vertebrae, linked to lateral flexion. Translations were never observed. 
Because in all birds the neck shares interspecific features, there must be a characteristic of the shape of the cervical vertebrae that are linked to the mobility of the different parts of the neck. These characteristics must be found in the joint shape, i.e. the link between the caudal part of a vertebra and the cranial part of the following vertebrae.

We hypothesized that the complex shape of the intervertebral joints encompasses a geometric principle shared by all species. As the joint surfaces are restricted to the zygapophysis articular surfaces and the centrum articular surfaces, modeling these surfaces only should make it possible to determine the geometric characteristics of the joint. The aim of the study was to design a joint model and test its usefulness for identifying the parameters involved in neck mobility.

\section{Material and Method}

\section{Material}

The 3D models of the mean vertebrae of Terray et al. (2020) were used. Module 1 is shared by all the species but one and was chosen for designing the geometric model. The swallow (Hirundo rustica, MNHN-ZO-AC-2000-733) and vulture (Gyps fulvus MNHN-ZO-AC-1996-43) vertebrae are the 3D models used by Terray et al. 2020. (see Terray et al. 2020 for the acquisition method.) Human Homo sapiens $\mathrm{C} 6$ and $\mathrm{C} 7$ vertebrae were downloaded from https://www.embodi3d.com/files/file/31822149 neck-ct/, and segmented using the CR2P 3D imagery service. The wolf Canis lupus ( MNHN-ZO-AC 20161665) was digitalized by the MNHN Surfacus service, and the mole Talpa europaea (MNHNZM.MO.1993.3218) was segmented by the authors.

\section{Geometric principle (Figure 2)}

In the cervical vertebrae of birds, the centrum articulations are modeled as a saddle-shaped joint (Kardong 2012). A saddle-shaped joint reduces the motion in allowing mainly two rotations, around $Z$ and $Y$ axis. These articulations could theoretically also permit some translations, allowing more than one center of rotation, which has never been described in birds neck intervertebral mobility. We used a ball and socket joint model for centrum articulation, which is more distant in terms of shape but fits well mechanically and helps to clearly identify a center of rotation and helps to clearly identify a center of rotation. Among the mechanical links, the rotule à doigt (RAD) (Aublin et al. 2005), a ball and a socket joint plus pin, allows rotations but no translation, as in the bird neck joints. The rotule à doigt (RAD) joint has no specific name in English so that we have kept the French one. We thus consider that the cervical spine can be assimilated to a series of modules linked by the RAD joint (Fig 2 A).

One module comprises one cranial socket, one long axis and one caudal ball plus the pin (Fig 2 B). Each joint is modeled as a RAD (Fig $2 \mathrm{C}$ ). The ball with the pin corresponds to the caudal part of a module and is the cranial part of the RAD joint. The socket is the cranial part of the next module and the caudal part of the RAD joint (Fig 2 C). This RAD joint blocks translations ( $T x=0, T y=0, T z=0$ ) and controls the rotations around one center of rotation depending on the shape of the socket and of the pin (Fig 2D, E, F).

\section{Modeling of the Intervertebral Joints}

We looked for the rotule à doigt structure in the shape of the intervertebral joint. We used a 3D 
mean vertebra from a module of Terray et al. (2020) to design the geometric model. A true bird vertebra fits only with its neighboring vertebrae, and thus, its cranial articulation does not fit with its caudal articulation. In contrast, the mean module vertebrae are repeated in the module, and their two articulations fit together. It was thus easier to find a geometric principle for the intervertebral joint. Then, we tested the validity of the geometric principle on the mean vertebrae of all the modules. To verify the usefulness of the model, we applied it to the cervical vertebrae of two very different bird species, in size, ecology and phylogeny: the griffon vulture Gyps fulvus and the swallow Hirundo rustica. To verify the validity of the model, we looked for it in the C6-C7 vertebral joint in three mammalian species with different phylogeny, sizes and behaviors: the wolf (Canis lupus), mole (Talpa europaea) and human (Homo sapiens).

Modeling of the intervertebral joints with the Module 1 mean vertebrae (Figure 3)

One module corresponds to the association of at least two identical mean vertebrae. A joint corresponds to the articulation between the caudal and cranial parts of the same mean vertebrae.

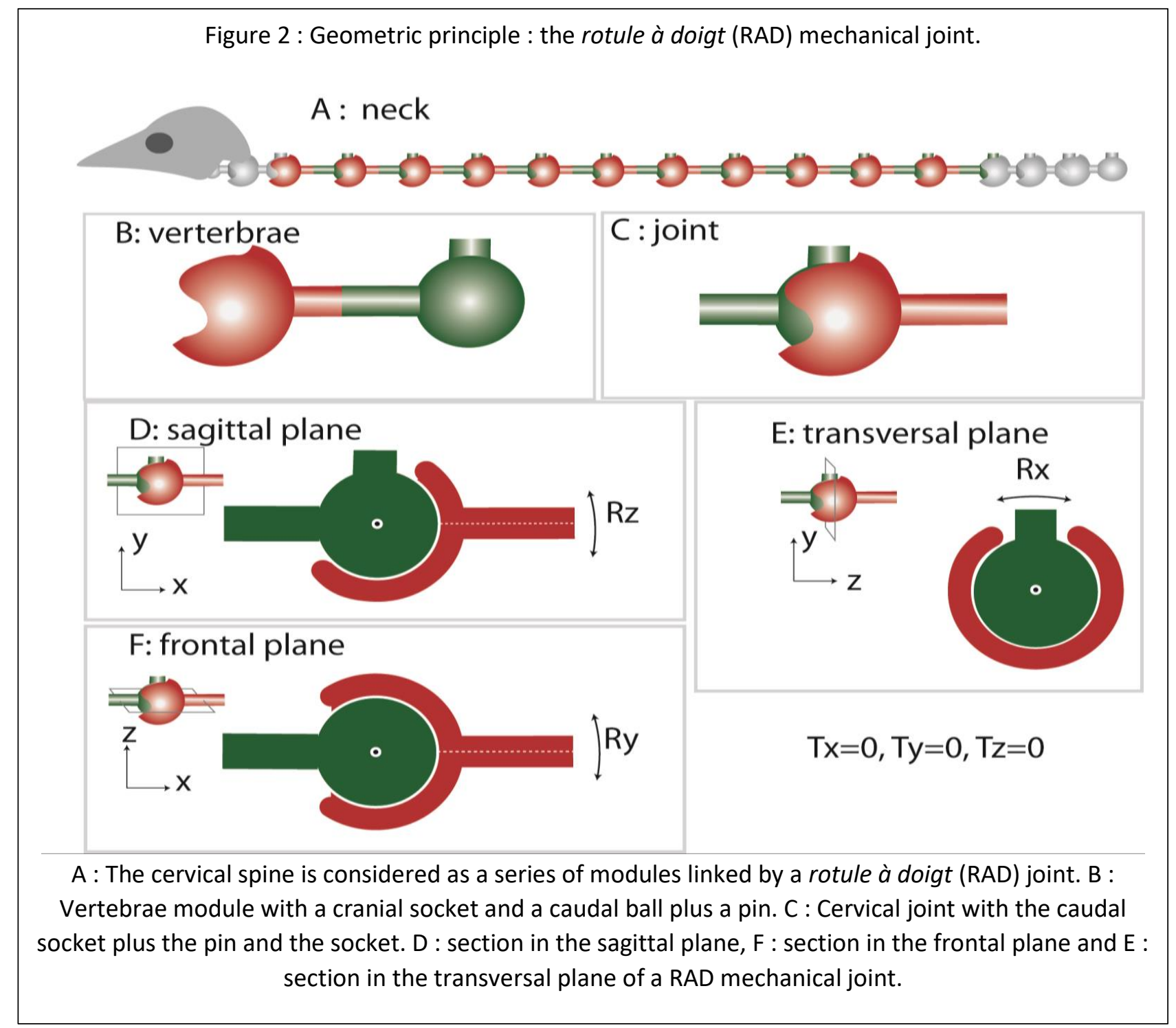


The 3D digital vertebrae were imported into the 3D edition and creation software Blender 2.82 (The blender foundation). The two surfaces of the centrum and the surfaces of the prezygapophysis and postzygapophysis were isolated. This allowed us to extract the 3D shape of the articular surfaces and to design a model, independently of the global shape of the vertebrae (Fig $2 \mathrm{~A}$ ). The geometric center of the articular surfaces of the centrum was identified and used as the center of rotation (CoR) of the system (Fig 3 B). Two spheres, centered on the CoR, passed through the middleof the

Figure 3. Cervical vertebra model. The 3D image of the Module 1 oblique cranial and caudal views (top), the lateral view (middle), and the cranial and caudal views (bottom)

A
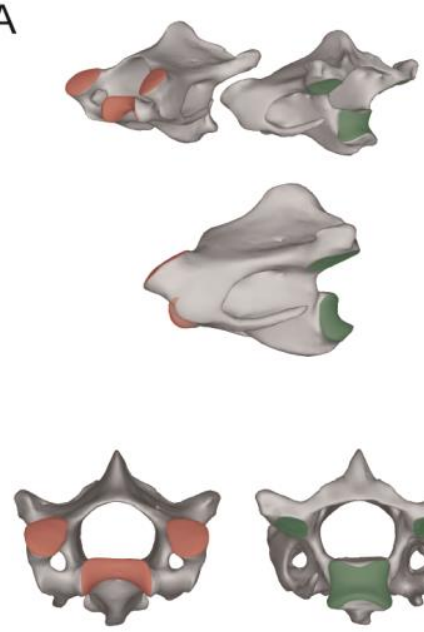

B
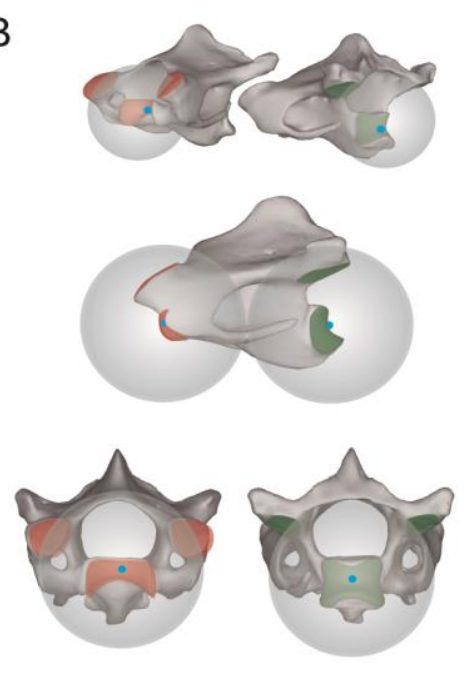

C
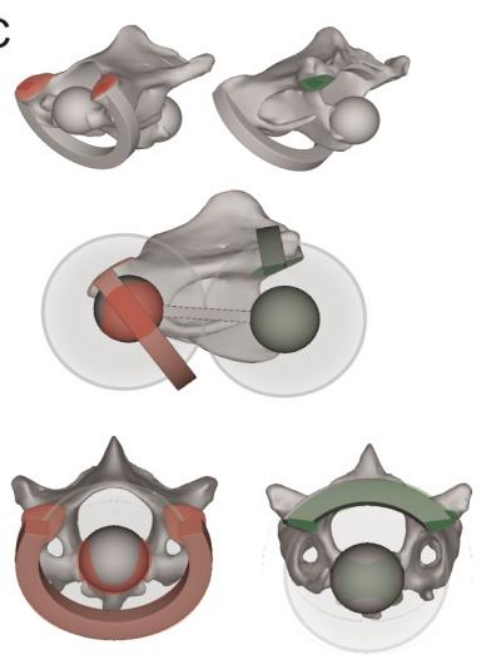

$\mathrm{E}$

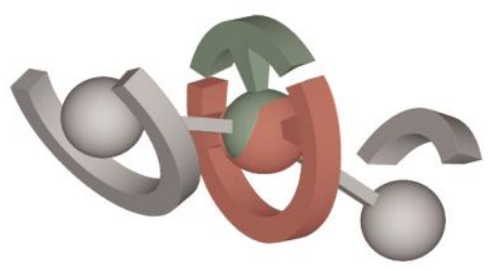

A: The articular surfaces are isolated on the 3D model, the cranial surfaces are in red, and the caudal surfaces are in green. B: The intervertebral movements take place around one center of rotation (CoR) of the joint. We placed them in the center of the centrum cranial and caudal articular surfaces (blue points). We built a virtual sphere centered on the CoR on the cranial and caudal joints. The sphere perimeters pass through the middle of the articular surfaces of the zygapophysis. C: An arc was cut out of the sphere, corresponding to the virtual material perpendicular to the articular surface of the zygapophysis. Cranially, the arc is ventral and below the prezygapohysis, and its cut surface corresponds to the prezygapophysis surface. Caudally, the arc is dorsal and over the postzygapophysis, and its cut surface corresponds to the postzygapophysis surface. A smaller part of the spheres is kept around the CoR cranially and caudally, adjusted to the centrum size. D: The joint between two vertebrae corresponds to the superimposition of the caudal and cranial spheres and therefore to the centers of rotation of the articular surfaces of the centrum of the two vertebrae. When two vertebrae are associated with the centra aligned, the caudal arc of the first vertebrae (green) is not above the cranial arc of the next vertebrae (red). The alignment of the arcs corresponds to the concordance of the articular surfaces of the zygaposphyses. It is achieved by rotating around the CoR of the joint and leads to a sagittal flexion of the joint. $E$ : The model behaves like a RAD joint, with the caudal ball fitted in the cranial socket, and the cranial arc below the caudal arc which plays like the pin of the RAD on the cranial arc below. 
zygapophysis articular surfaces Fig 3 B). Two arcs are "cut out" from the spheres, corresponding to slices of the sphere passing through the articular surfaces of the zygapophyses and centered on the CoR (Fig 3 C). The prezygapophysis arc is ventral, and the postzygapophysis arc is dorsal. The arcs are virtual and don't correspond to an anatomical structure. Their cut was superimposed on the articular surface of the zygapophysis (Fig $3 \mathrm{C}$ ). The intervertebral joint corresponds to the interlocking of the

centrum joints by the superimposition of the CoR (Fig $3 \mathrm{D}$ ). When the two centra are aligned, the arcs may not face each other (Fig 3 D). The face-to-face positioning of the two arcs, the postzygapophyses of a vertebra and the prezygapophyses of the next vertebra may lead to sagittal flexion of the joint (Fig $3 \mathrm{D})$.

In the schematic model (Fig 3 D), the centrum axis corresponds to the system to be moved, i.e. the vertebrae. The CoR of the joint (Fig 2), corresponds to the geometric center of the centrum surfaces. The dorsal arc, which represents the pin linked to the ball of the RAD (Fig 2), corresponds to the postzygapophyses. The ventral arc, the socket (Fig 2), corresponds to the prezygapophyses.

In this schematic joint, the CoR is constrained at the geometric center of the centra. This simplification allows to understand the relationship between the combined motion of the six articular surfaces. The mobility is constrained by the position of the two arc cuts related to the CoR and to each other. No translation is allowed, and the rotation around the longitudinal axis is restrained by the two arcs. The rotations around the transverse axis and the lateral axis are allowed but can be restrained by the orientation of the arc cuts. The mobility of the model is the same as that in a RAD joint.-

\section{Geometric Parameters (Figure 4)}

$\square$ The position and orientation of the cuts play a role in the joint mobility when the two arcs are superimposed (Fig. 4). Around the X-axis (longitudinal), a distance between the dorsal and ventral surfaces may allow some rotation. Around the Z-axis (transverse), the length of the surface contributes to mobility. Around the Y-axis (dorsoventral), the obliquity of the surfaces may also block rotation.

The orientation of the zygapophysis surfaces, corresponding to the cut in the model, may have basic function in terms of the mobility of the cervical axis.

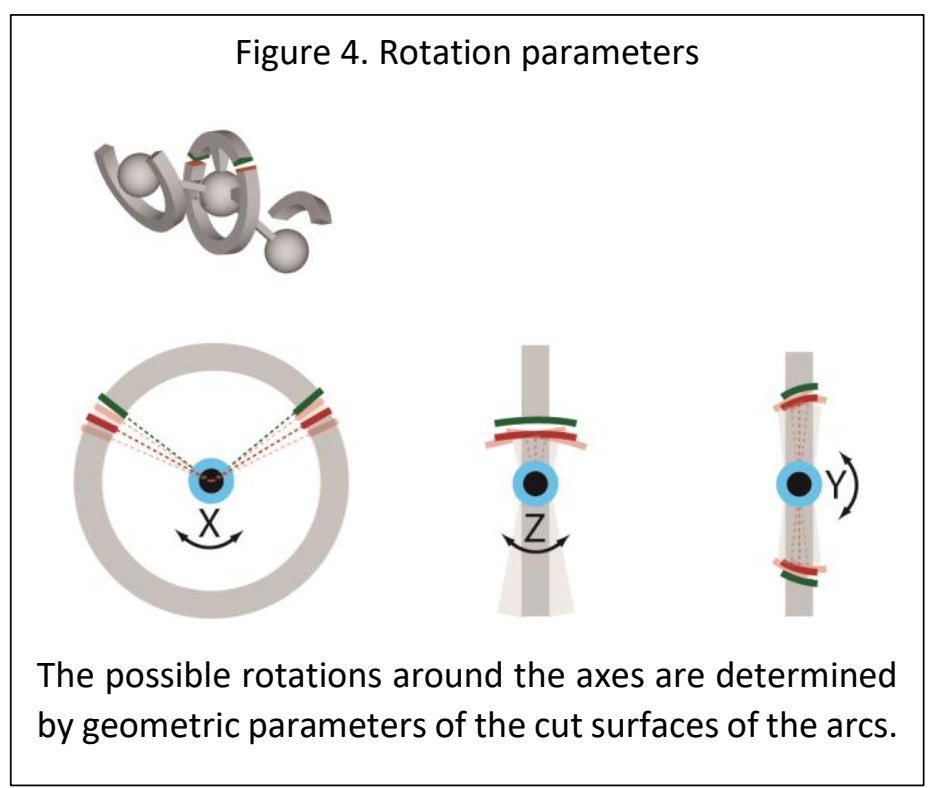

\section{Mobility (Figure 5)}

Therefore, the variables that guide mobility in the model are the position of the arcs toward the centra. This position parameter is measured using the line passing through the center of the arc cuts and the CoR. The position angles are the angle between the position line and the transversal plane in lateral view (Fig 5A), and between the position line and the sagittal plane in transversal view (Fig B). The position angles allow us to calculate the neutral position of the joint, which is determined by the angle between the two vertebra centrum axes when both the dorsal and ventral arcs are aligned in the joint (Fig 5C), i.e. when the position lines of the zygapophysis are superposed in lateral view

The orientation of the cut surfaces of the arcs also guides the mobility. This orientation parameter is measured by the angles between the normal vector of the cut plane in the sagittal plane (Fig 5 D F) and the 
Figure 5 Geometric variables on the model

A
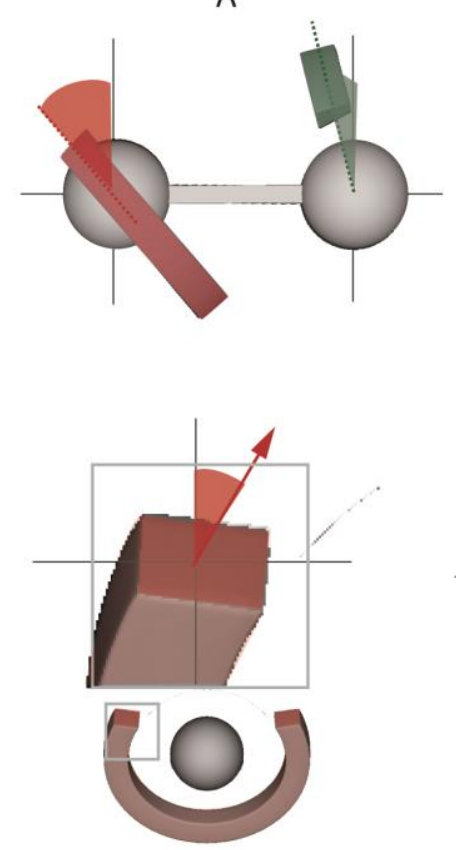

D
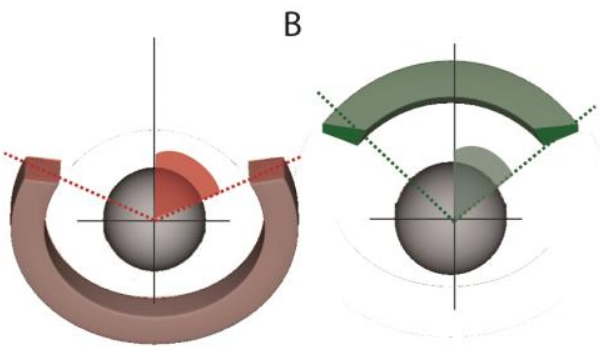

C
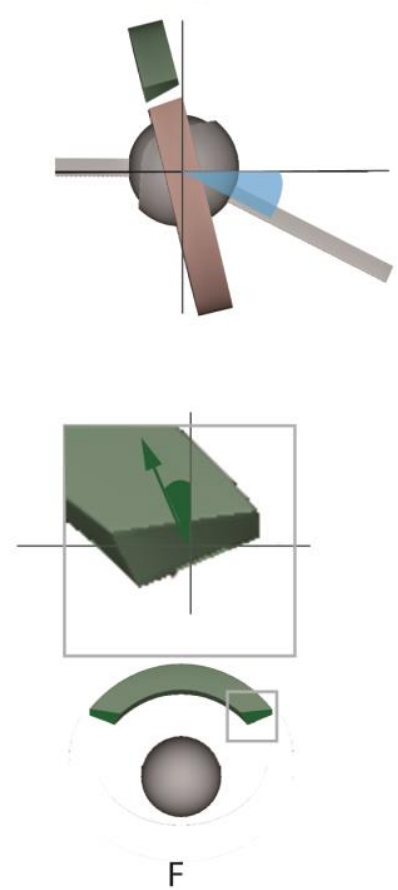

Cranial arc in red and caudal arc in green A, Sagittal position: angle between the arc axes and the transversal plane ; $B$, transversal position :angles between the arc axes and the sagittal plane; $C$, Body angle : angle between the cranial vertebra centrum axis and the caudal vertebra centrum axis when the arcs are facing each other; $D$, sagittal surface orientation : angle between the normal vector of the cranial arc cut (D) and the caudal arc cut (F) and the sagittal plane; $\mathrm{E}$, transversal surface orientation : angles between the arc cut normal vectors and the transversal plane.

\section{Application of the model on biological material (Figures 6 and 7)}

We imported the digital models of the vertebra in landmarks (IDAV) V3.0.0.6, the software of landmark editing. We digitized the Cartesian coordinates of 13 points (Fig 6, SM Table 1).

Figure 6 Digitized landmarks. Module 1 mean vertebrae,

A

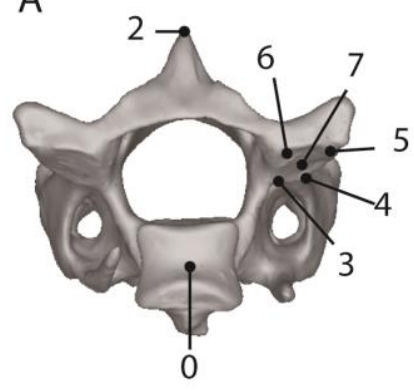

B

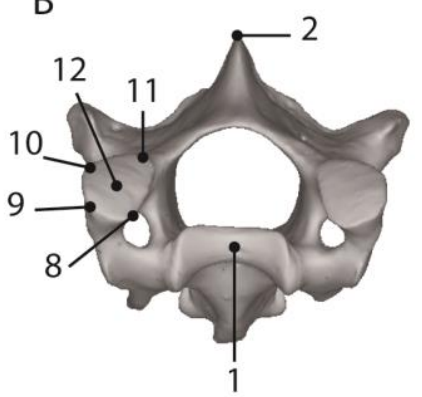

A, caudal view; B, cranial view. The points were chosen in order to represent the zygapophysis surfaces and the vertebral body axis, corresponding to the geometric variables of the model. 
To be able to align all the vertebrae in the same anatomical space (Krings et al. 2014) a rotation matrix was calculated (Fig 7). We used three points to define the anatomical sagittal plane : the cranial and caudal centers of the centrum surfaces (points 0 and 1 ) and the sagittal point on the neural spine (point 2). The $X$ axis passes through the points 0 and 1 , the $Y$-axis passes through the point 2 and is perpendicular to the $X$-axis in the dorso-ventral direction. The $Z$-axis is perpendicular to the $X$ and $Y$ axes, in the latero-medial direction. The sagittal plane is defined by the $X$ and $Y$ axes. The frontal plane is defined by the $X$ and $Z$ axes. The transversal plane is defined by the $Y$ and $Z$ axes (Fig 7 A).



We fixed the origin of each vertebral anatomical space in the center of the caudal centrum surface (point 0). Using trigonometric formulae, we calculated the Euler angles between the center of the zygapophyses (points 7 and 12) and the CoRs (points 0 and 1 ) in the 3 directions of the anatomical plane and a line perpendicular to the vertebral body axis in the sagittal plane. In the sagittal plane, the sign of the angle indicates its position toward the CoR. The angle was positive when the vertebral body center was cranial to the zygapophysis center, and negative when it was caudal to the zygapophysis center. (Fig 7 B).

To study the joints, we fixed the Vi vertebrae anatomical space and superimposed its caudal CoR and the $\mathrm{Vi+1}$ cranial CoR. We rotated the $\mathrm{Vi+1}$ centrum axis around the CoRs so that the surfaces of the zygapophyses faced each other. We were then able to calculate the coordinates of the $\mathrm{Vi+1}$ prezygapohysis points in the anatomical space of the Vi vertebrae. It was then possible to look at the position of joints with the vertebrae in their neutral position (SM Fig 1).

We also calculated the orientation of the zygapophysis surfaces toward the sagittal and transverse planes. As the surfaces are not planar, we approximate a plane by using only three points on the surface, respectively on the postzygapophysis and the prezygapophysis : the most medio-caudal point (points 3 and 8), the most latero-cranial (points 5 and 10) and the most latero-caudal (point 6 and 11). We calculated the coordinates of the normal vectors, in the sagittal plane (OXY) and in the 
transverse plane (OYZ), then we calculated the angles between the normal vectors and the transversal and sagittal planes. In the sagittal plane the sign of the angle indicates its orientation toward the CoR. The angle was positive when the vertebral body center was cranial to the zygapophysis center, and negative when it was caudal to the zygapophysis center. (Fig $7 \mathrm{C}$ ).

\section{Results}

\section{Module mean vertebrae (Fig 8 II, Fig 9 II, SM Fig 1)}

The mean vertebrae are presented depending on the module position along the neck, from the cranial position (M1 and M9) to the middle position (M2 and M5) to the prethoracic position (M3, M6, M7, and M8). Depending on the module, the position of the zygapophysis toward the vertebral body is different.

In the sagittal plane XY (Fig 8, II A, SM Fig 1) the post-and prezygapophyses may be positioned both in the same direction, cranially (M1; $9 ; 3 ; 7 ; 8)$ or caudally (M5). They may be positioned differently: caudally and cranially (M2) or cranially and caudally (M6).

In all the module mean vertebrae, on the projections on the transverse plane YZ (Fig 8 II B) the position angle of the prezygapophysis is slightly larger than the position angle of the postzygapophysis. This corresponds to the dorsal position of the postzygapophyses in regard to the prezygapophyses. In module 1, differences between the pre- and postzygapophysis were larger than in the other modules. The position angle in the transverse plane corresponds to the more or less dorsal position of the zygapophysis. The more lateral the zygapophysis (i.e. the larger the angle), the more ventral its position is toward the centrum, as in module 1.

In the frontal plane (Fig8 II C), the position is very similar to those in the sagittal plane and will not be detailed further.

The sagittal flexion of the joint (Fig 8 II D) is not a function of the direction of the position of the zygapophysis. With both zygapophyses positioned_cranially, the M1 articulation corresponds to ventral flexion of the joint. M6, with the postzygapophysis positioned cranially and the prezygapophysis positioned caudally, also articulates as ventral flexion. The articulation of the vertebrae may result in a rather straight joint regardless of the position of the zygapophysis, cranial or caudal, similarly for M9 and M3. The flexion of the joint depends on the position of the two zygapophyses toward each other. A postzygapophysis more cranially positioned than the prezygapophysis, as in $\mathrm{M} 2$ or $\mathrm{M} 5$, induces dorsal flexion when overlapping. A postzygapophysis more caudally positioned than the prezygapophysis induces ventral flexion when overlapping, as in M1 or M6.

The articular surfaces are not planar, and the normal vector represents an estimation of a mean orientation. It gives an idea of the general pattern. As the normal vector is perpendicular to the surface, the more parallel it is to a plane, the more perpendicular to this plane is the surface. Laterally (Fig 9 II A), in module 1, 9 and 3 the orientation angle is smaller in the prezygapophysis than in the postzygapophysis, indicating a more transversal orientation of the prezygapophysis surface. In modules 2 and 6, the postzygapophysis surfaces are more transversal than the prezygapophysis surfaces (i.e. there is a larger orientation angle), and in modules 5, 7 and 8 the orientation of the two surfaces is parallel. 
Figure 8 Measurements of the zygapophysis axes : position parameters

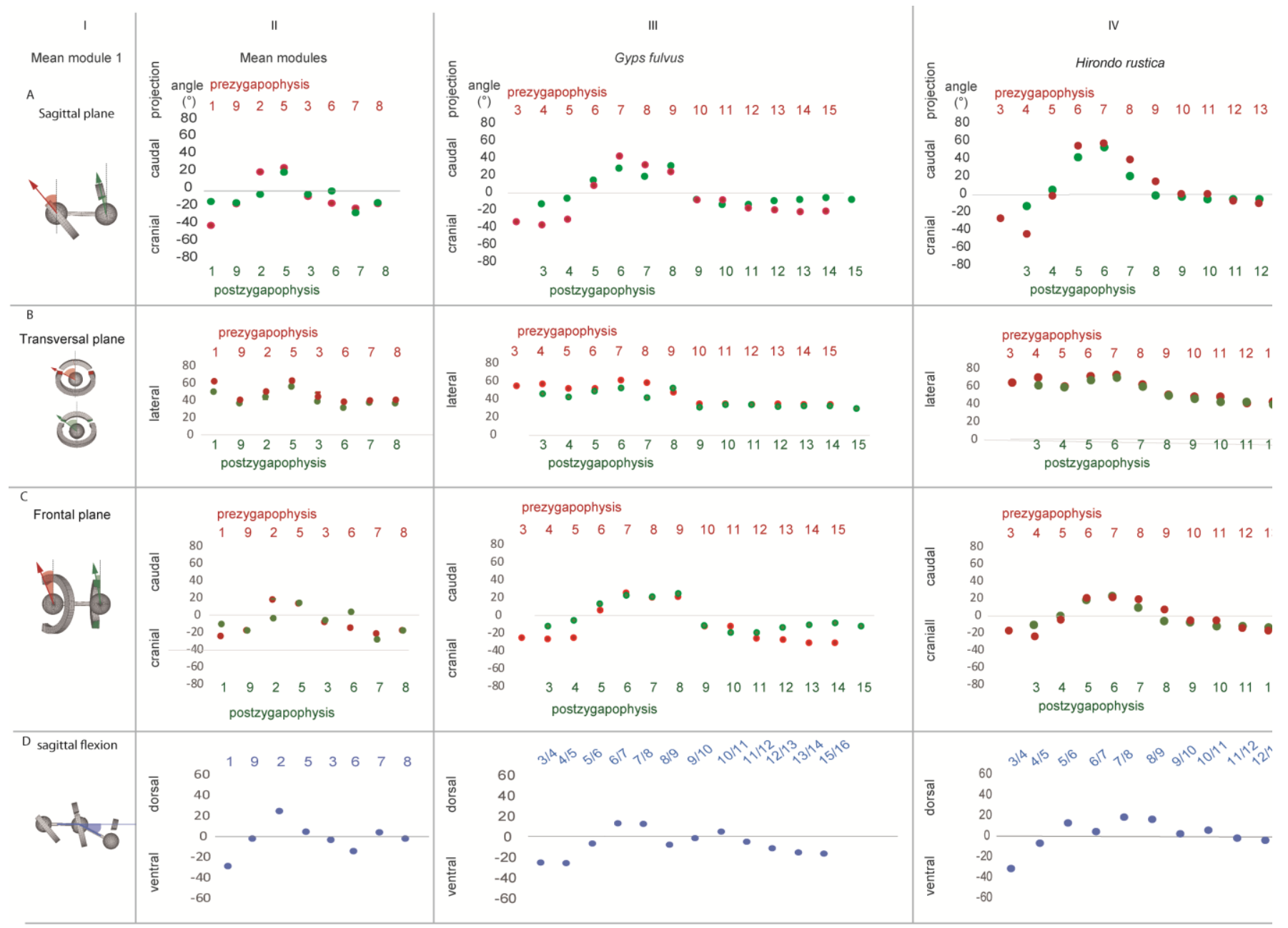

Figure 9 Measurements on the zygapophysis surfaces: orientation parameters

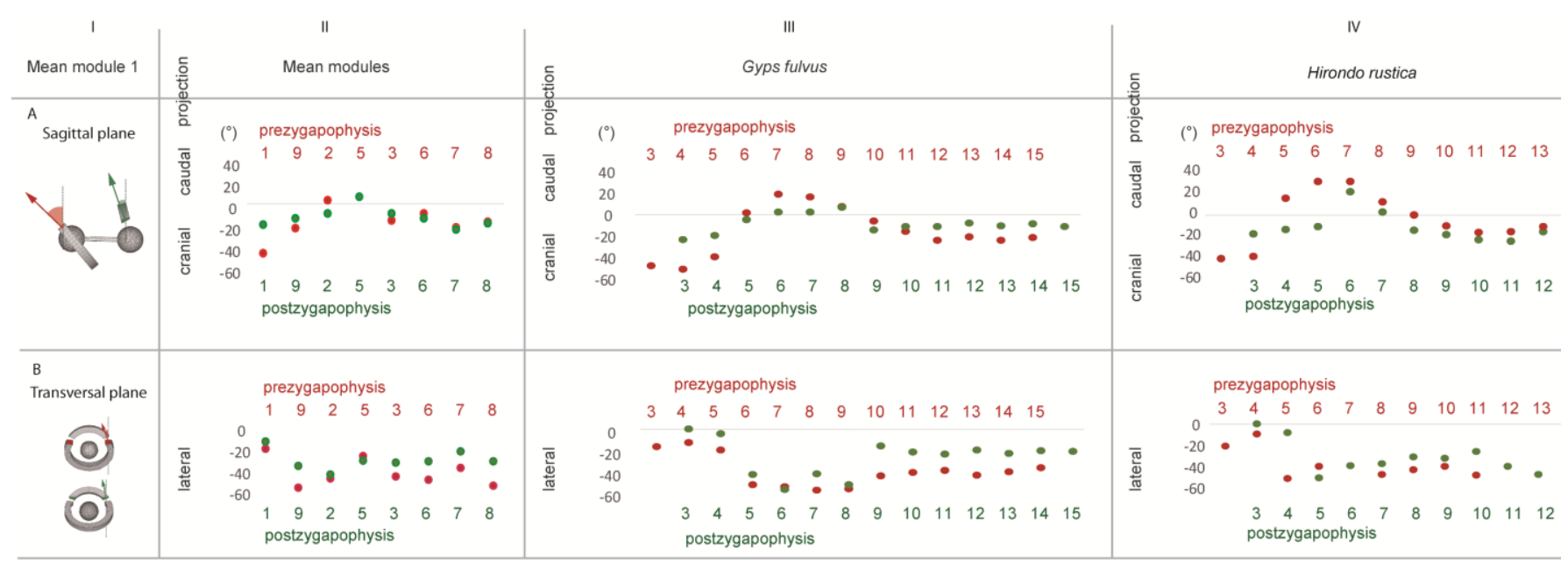

Each row presents the position angles ( fig 8) and orientation angles (fig 9) measured on the different planes. Column I: the measurements are illustrated on the mean module 1 . Column II: measurements of the module mean vertebrae. Column III : measurements of the Griffon vulture (Gyps fulvus) vertebrae. Column IV : measurements of the swallow ( Hirundo rustica) vertebrae.

For the vulture and the swallow, the measurements of the pre-and postzygapophyses of the same vertebra are shifted to the graphs so that the postzygapophysis of the vertebra Vi (green graduation at the bottom) is associated with the prezygapophysis of the vertebra $\mathrm{Vi+1}$ (red graduation at the top) as in the joints. On the sagittal views, the negative values correspond to a caudal position of the vertebra centra toward the zygopophysis, thus a cranial position of the zygapophysis and conversely, positive values correspond to the caudal position of the zygapophysis. 
In the sagittal plane (Fig 9 II a), globally, the orientation angles change in the same way as the position angles (Fig 8 II A). As this position of the zygapophysis is linked to the sagittal flexion of the joints, it appears that the sagittal orientation of the surfaces globally participates in the sagittal flexion. However, in module 9, the prezygapophysis surface is less oblique than its position.

In the transverse plane, the orientation angle (Fig 9 II B ) follows the position angle depending on the modules (Fig 8 II B). However, whereas the position of the two zygapophyses of a module are very close, the differences between the orientation may be large. These differences are larger when the surfaces are more parallel in the sagittal plane (Fig 9 II A). For instance, in modules 1 and 2, the differences are larger in the sagittal plane than in the transverse plane. In modules 9, 3, 6, 7, and 8, the difference in the sagittal plane is smaller than that in the transverse plane. Nevertheless, in module 5 , the orientation of the surface is close in all directions.

The difference between the surface orientations in the sagittal plane (Fig 9 II A) corresponds to the neutral flexion of the module joint (Fig 8 II D) as does the zygapophysis position (Fig 8 IIA). The orientation in the transverse plane corresponds to the mobility. The more frontal the surfaces are, the more perpendicular to the $\mathrm{Y}$-axis they will be and more rotation around $\mathrm{Y}$ will be possible, as in module 1. In module 2, the surfaces are both very close and rather parasagittal and block rotation around $\mathrm{Y}$. The zygapophysis positions may be more parallel than the surface orientations (module $9,3,6,7,8)$ and may guide the lateral mobility differently depending on the sagittal flexion of the joint. The difference in the positions in the transverse plane leads to mobility around the X-axis (Fig 4). The surface orientation corresponds to the limitations of mobility. Differences in the post- and prezygapophysis surface orientations may lead to a limitation in mobility depending on the sagittal flexion of the joint.

Moreover, in the vertebrae, the articular surfaces are not planar, and their shapes must be adjusted in such a way that they permit more or less mobility depending on the flexion of the joint.

Tests on the necks of two avian species Gyps fulvus and Hirundo rustica (Figure 8 III, IV and Figure 9 III and IV, SM Figure 1)

In the bird vertebral column, the pre- and postzygapophyses of a vertebra do not articulate together but with the neighboring vertebra. The results are presented to highlight this feature: the measurements on the postzygapophysis (in green) of the $\mathrm{N}$ vertebrae face the measurements on the prezygapophysis (in red) of the $\mathrm{N}+1$ vertebrae.

Sagittal plane (Fig 8 A) In the vulture G. fulvus, as in the swallow H. rustica, the same overall pattern exists, and it is the same as that in the module mean vertebrae: The post- and prezygapophyses may be positioned both in the same direction, cranially (G. fulvus 3,4,10,11,12,13,14,15; $H$. rustica: $3,10,11,12,13)$, caudally (G. fulvus $6,7,8 ; 339$ H. rustica 6,7$)$, or differently (G. fulvus 5,$9 ; H$. rustica 4, 8,9).

As for the module, the sagittal (Fig 8 D), ventral or dorsal flexion of the joint depends on the difference between the two zygapophysis position angles. In both species, the sagittal flexion is ventral near the head, dorsal in the middle of the neck and slightly ventral in the prethoracic region. In the transverse plane (Fig $8 \mathrm{~B}$ ), the overall pattern was the same in both species, with more tilting near the head (larger angle toward the sagittal plane) and more holding up near the thorax (smaller angle toward the sagittal plane). For the modules, the pattern in the frontal plane (Fig $8 \mathrm{C}$ ) was almost the same as in the sagittal plane. However, in the middle part, in joints 6-7 and 7-8 of the vulture and joint 5-6 of the swallow, the positions of the zygapophysis were almost the same, whereas they did not in the sagittal plane. 
The sagittal orientation of the zygapophysis surface exactly followed the pattern of the zygapophysis position in the vulture (Fig 8 III A and Fig 9 III A) but not in the swallow. In the 4-5 and 5-6 joints, the prezygapophysis (in red) orientation roughly changed with their position but the postzygapophysis maintained the same orientation, forming a large difference between the surface orientations in the joints.

In both species, the positions of the zygapophysis corresponded to the overall flexion pattern of the neck (Fig 8 D), with a more ventrally flexed part near the head, a dorsoflexed part in the middle of the neck and a more or less straight part near the thorax. However, the different parts involve more or less joints. For instance, three joints are ventro-flexed in the cranial part of the vulture, and two joints are ventro-flexed in the swallow. In the middle part of the neck, two joints (6-7 and 7-8) are dorso-flexed in the vulture, but four in the swallow (from 5-6 to 8-9).

The overall pattern was found in the cases of the modules, the vulture and the swallow, validating the usefulness of the RAD model for understanding the avian intervertebral geometry.

\section{Interpretation (Figure 10, 11)}

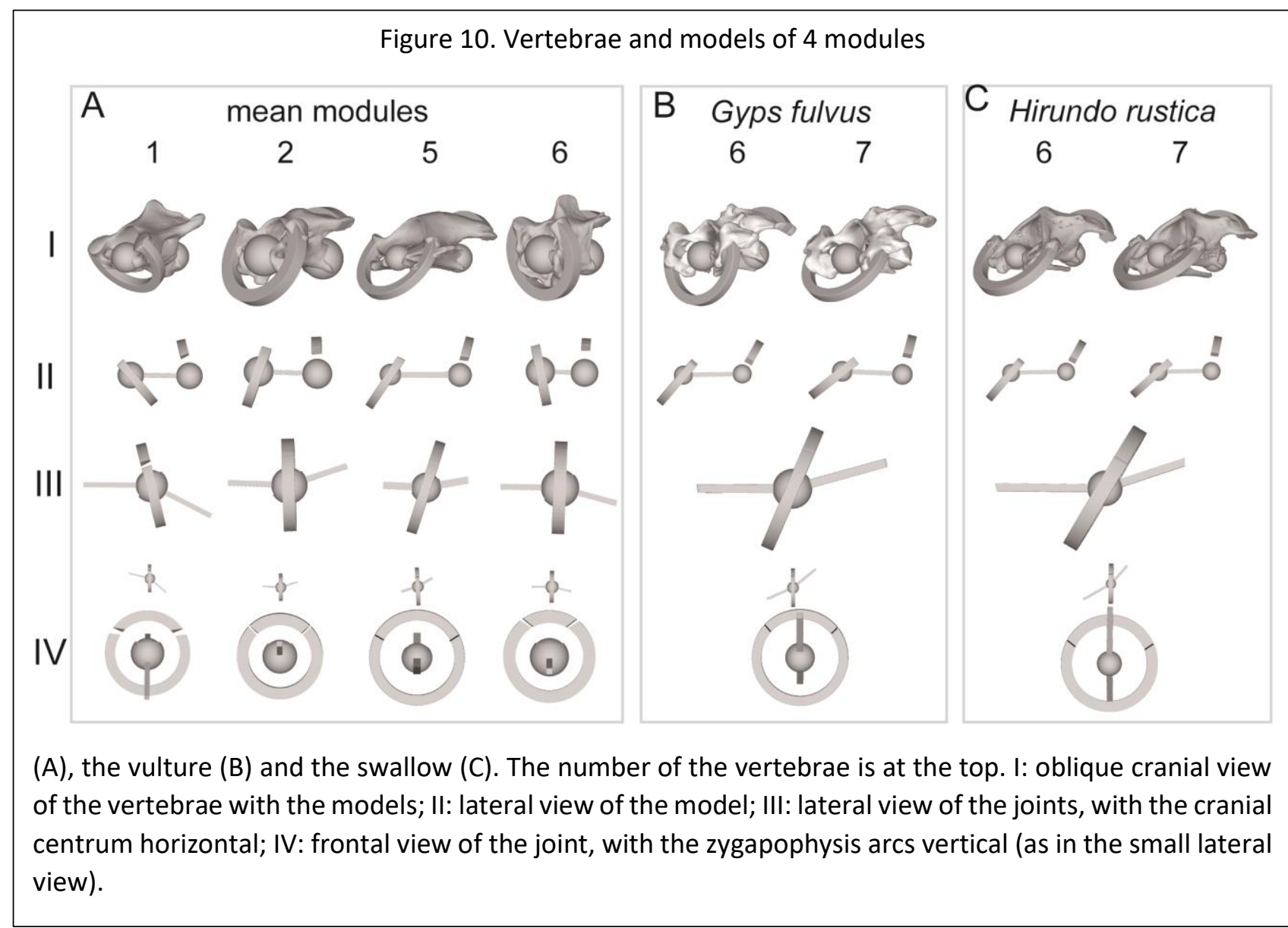

In the joints, the surfaces of the zygapophysis facing each other imposes a configuration with a specific sagittal flexion of the joint in the neutral position. With that configuration, a rotation around the Z-axis (i.e. dorso-ventral flexion) as well as around the Y-axis (i.e. latero-medial flexion) is allowed as long as the two pairs of zygapophysis surfaces slide over each other.

For instance, in module 1, which corresponds to the vertebrae following the atlas and axis in the sagittal plane, the difference in the position of the pre- and postzygapophysis is $28^{\circ}$ (Fig $10 \mathrm{~A}$ II), imposes an angle between the centra is $-28^{\circ}$ and thus in ventral flexion (Fig $10 \mathrm{~A}$ III). In the same plane, the differences in orientation of the surface are nearly the same $\left(26^{\circ}\right)$, and one can consider them to be parallel. The zygapophysis is rather medially positioned $\left(62^{\circ}\right.$ and $\left.37651^{\circ}\right)$, and the 
surfaces are almost parallel and thus laterally oriented (Fig10 A IV). The surfaces can slide over each other, allowing lateral flexion. The two surfaces are almost parallel, and it appears that this slight difference could permit an adjustment depending on the sagittal flexion of the joint. The $10^{\circ}$ difference in the positions induces a gap between the two surfaces, which could also give some play to the joint and permits some axial rotation.

In module 2, corresponding to vertebrae in the middle part of the neck, the difference in the position of the zygapophyses induces dorsal flexion of the joint in the neutral position. The zygapophyses are positioned_more medially than in module $1\left(50,44^{\circ}\right)$, the surfaces are more sagittal. The small gap between the surface may allow some lateral flexion depending on the sagittal flexion of the joint.

In module 5, which is also found in the middle part of the neck, in the sagittal plane, both zygapophyses share a similar cranial position $\left(27^{\circ}, 22^{\circ}\right)$, and the neutral position of the joint is straight. The zygapophysis are laterally positioned $\left(63^{\circ}, 56^{\circ}\right)$. The surfaces of the zygapophysis also share similar orientations in the sagittal and transverse planes $\left(\left(13^{\circ}, 7^{\circ}\right)\right.$ and $\left(27^{\circ}, 30^{\circ}\right)$, respectively). This shape suggests rather constrained mobility of the joint

In module 6, found before the thoracic column, the difference in the sagittal position of the zygapophyses $\left(11^{\circ}, 3^{\circ}\right)$ induces a small ventral flexion in the neutral position, and the position in the transversal plane $\left(39^{\circ}, 32^{\circ}\right)$ constrains lateral flexion of the joint. The surface orientations in the sagittal plane are close $\left(15^{\circ}, 9^{\circ}\right)$, and in the transverse plane, they are more different $\left(44^{\circ}, 31^{\circ}\right)$. The transverse surface difference $\left(13^{\circ}\right)$ is almost the same as the difference between the positions in the sagittal plane $\left(14^{\circ}\right)$. This shape suggests, as in module 5 , rather constrained mobility of the joint.

In the vulture and swallow, the most cranial vertebrae are clustered within module 1 In the middle part of the neck, the vulture vertebrae were clustered within module 2 , and the swallow vertebrae of the middle part were clustered within module 5 (Terray et al, 2020). The $5^{\text {th }}$ and $6^{\text {th }}$ vertebrae of both birds look similar to the sagittal plane (Fig $10 \mathrm{~B} \mathrm{C} \mathrm{II} \mathrm{and} \mathrm{III)),} \mathrm{even} \mathrm{if} \mathrm{the} \mathrm{dorsal} \mathrm{flexion} \mathrm{is} \mathrm{slightly}$ higher in the swallow. In the transverse plane (Fig $10 \mathrm{~B}, \mathrm{C}$ IV), the frontal view shows that the zygapophyses are more lateral in the swallow, as they are on the module 5 , than in the vulture and the module 2 . In both cases, both the pre- and postzygapophyses were very close, suggesting very little lateral mobility.

\section{Validity on mammal cervical joints (Figure 11)}

We used the bird cervical column as a case study to propose a mechanical joint for the intervertebral joint. In order to test its validity in other taxa, we looked for it on the C6-C7 joints of three very different mammal species: wolf (Canis lupus), mole (Talpa europaea), and human (Homo sapiens) (Fig 11).It was possible to find the RAD model in the C6-C7 intervertebral joints in mammals despite their differences with the birds. The main differences in the centrum shape are: $1 /$ The centrum articular surfaces which have a saddle shape in birds are concave cranially and convexe caudally in the wolf, and rather flat in the human and the mole. 2/ The presence of an intervertebral disc in mammals inserts a space between the centra. In human, the studied horizontal position of the vertebrae is different from the position when standing (Fig 11 a) but allows an easier comparison with the other species. Despite the differences in the centrum articular surface shape the RAD mechanical joint is also found in these mammal's cervical joints (Fig 11) 
Figure $11 \quad$ C6-C7 Vertebrae and joint models in three mammal species: the wolf, the mole and the human.

Canis lupus

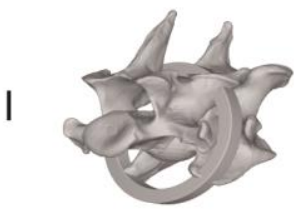

II

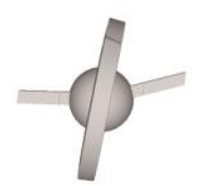

III

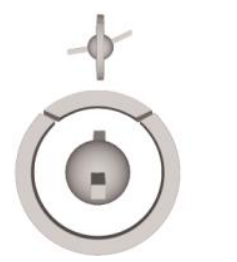

Talpa europaea
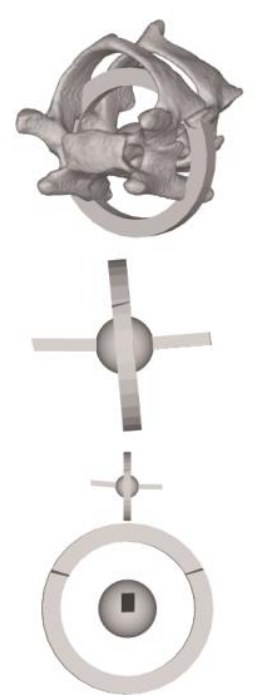

Homo sapiens
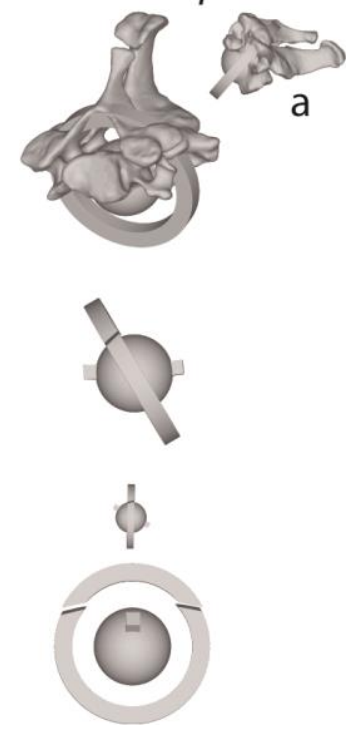

The $\mathrm{C} 6$ centra in horizontal position.

Row I: C6-C7 vertebrae and models in $3 / 4$ lateral view, first column the wolf, second column the mole, third column the human. a: Human $\mathrm{C} 6-\mathrm{C} 7$ seen in standing position. Row II: joint model, lateral view, Row III: joint model, frontal view, the arcs in vertical position as shown in the small lateral view above the frontal view.

\section{Discussion}

The RAD mechanical joint is convenient for a bird intervertebral joint model because it integrates all the articular surfaces involved in the mobility of the articulation in a single joint. Once the RAD joint was identified as a mechanical candidate, we were able to find them on Terray's modules' mean vertebrae, which are simpler than real vertebrae because they articulate with themselves. The measurements of the vulture and swallow cervical column showed that the joint model is also suitable for studying the complexity of real avian vertebrae. The comparison of the joint between the $5^{\text {th }}$ and the $6^{\text {th }}$ vertebrae of these birds and of the three mammals showed that it is also suitable for different mammal species.

The aim of the study was to design a joint model and test its usefulness for identifying the parameters involved in neck mobility. The joint model consists of two arcs, a dorsal arc and a ventral arc that share 426 the same radius. The dorsal arc is linked to a central ball, and the ventral arc is linked to a central socket. The ball and socket fit together in a joint sharing the same CoR. The ball is associated with an anterior bar and the socket with a posterior bar. The geometric parameters are the position of the arcs toward the bars, and the relative place and orientation of the arc-cut surfaces toward each other (Fig $3 \mathrm{E}$ and Fig 4). With the assumption that the neutral position of the joint is found when the two arcs face together, the geometric parameters define the mobility of the joint. One vertebra comprises two half joints: the cranial ventral arc system and the caudal dorsal arc system, linked by their bar. On the vertebrae, the 3D measurement of the positions of the centrum articular surface geometric centers and the position and orientation of the zygapophysis surfaces allow us to set the joint mobility parameters.

The test of the modules and real vertebrae showed that the model can explain the overall features 
of a bird's neck: the S-shape (Boas 1929) and the sagittal flexibility (Bout 1997, Van der Leeuw et al 2001, Krings et al 2014, Kambic et al 2017) are explained by the sagittal position of the arc radius (position of the zygapophysis) toward the bar (centrum). The longitudinal rotation lock along the neck (Krings et al.2017) and its small range in the first vertebrae (Kambic et al_.2017) are explained by the shapes and the orientation of the dorsal and ventral arc cuts (i.e the surfaces of the zygapophysis).

The comparison of the measurements of the vulture and the swallow shows differences in the most cranial part of the neck, with the two joints (3/4 and 4/5) in the vulture and one joint (3/4) in the swallow sharing the module mean vertebra features: differences in the position leading to ventral flexion and differences in the surface orientations allowing lateral flexion and some degree of longitudinal mobility. A functional explanation could be that for the vultures, these two joints allow great mobility of the head, which is useful for pulling meat from the inside of a carcass, a mobility that would not be necessary in the behavior of swallows. The RAD is also found in the wolf, the mole and the human. As they are very distant phylogenetically and quite different in size and behavior, it looks like the RAD mechanical joint is a shared model for mammals as well as birds.

The model provides a theoretical framework for studying cervical joints. It allows the extraction of parameters for shape and mobility. It will be very useful to analyze neck mobility in different species. It allows comparison and can thus be used for functional interspecific analysis. Because we looked for a joint model in this study, we did not look at the vertebrae length, which is the basic part of the bird neck (Böhmer et al. 2019). This is measured as the distance between the two centrum surfaces of the vertebrae. It must be considered in further studies.

In the model, the articular surface shapes are not studied. The vertebral body surfaces are simplified and treated like a ball and socket, with one center of rotation. It is clear they are much more complex and diversified. In birds, the saddle shape constrains the joint mobility (Kardong 2012), differently than a ball and socket does. However, the zygapophysis position and orientation are determinants and seems sufficient to explain the mobility. A more accurate study_including the measurement of the mobility on articulated necks are needed to validate this point.

In mammals, the intervertebral discs induce a space between the articular surfaces_and their mechanical properties also constrain the mobility. In dogs, the intervertebral disc and the ligaments influence the range of motion but the structure of the motion is determined by the orientation of the zygapophyses and the transverse distance between them (Breit and Künzel 2002). Amevo et al. 1991 measured that in the human cervical joints the instantaneous axes of rotation are not positioned on the centra articular surface, that their places are different from joint to joint and that their positions change depending on the cervical movement. These differences are determinant in a medical context because the very fine adjustment of intervertebral motion is fundamental in orthopaedics. It is clear that the RAD model is not relevant in this context. However, Wang et al. (2020) used the orientations of the six articular surfaces involved in the vertebrate joint, as does the RAD model, in measuring the range of motion of the human cervical spine. Using X-ray and tomographic images, they were able to consider the space between the articular surfaces. This method allowed them to measure the vertebrae range of motion in the human cervical spine. Thus, the RAD, modified to include the intervertebral disc could be useful for comparison between humans and other species.

We are confident that the RAD intervertebral joint model makes it possible to extract from the complex shape of the vertebrae the parameters that guide and limit mobility. It becomes possible to quantify these parameters in comparative series. It will allow interspecific studies and thus permit a better understanding of the morpho-functional adaptations during evolution. The next steps will 
be to validate the RAD in large interspecific samples and to compare the results with measurements on articulated cervical spines.

Acknowledgments: We thank Christine Lefevre, Aurélie Verguin and Celine Bens for access to the MNHN bird osteological collection. We thank Delphine Braband from the Surfacus service of the MNHN Collection of scanning specimens and Florent Goussard from the Imagerie 3D service of the CR2P for help with mammalian vertebrae digitization. We also thank the referees for their very relevant and constructive remarks.

The work was funded by the ANR Avincek project (16-CE33-0025 A Abourachid, coordinator). The data that support the findings of this study are available from the corresponding author upon reasonable request 


\section{Bibliography}

- Amevo B, Worth D, Bogduk N (1991) Instantaneous axes of rotation of the typical cervical motion segments : a motion in normal volunteers. Clinical Biomechanics, 6 : 111-117

-Aublin M., Boncompain M.R., Boulaton M., Caron,D., Jeay E., Lacage B., Réa J. (2005) Systèmes Mécaniques : théorie et dimensionnement, Paris, Dunod.

- Arbour VM, Zanno LE. 2018 The evolution of tail weaponization in amniotes. Proc. R. Soc. B 285: 20172299. http://dx.doi.org/10.1098/rspb.2017.2299

- Breit S, Künzel W (2002) Shape and Orientation of articular facets of cervical vertebrae (C3-C7) in dogs denoting axial rotation ability an osteological study. European J Morphology 40 (1): 43-51.

- Boas J, E., V. (1929) Biologisch-anatomische Studien über den Hals der Vögel. Kgl. Danske Vidensk. Skrifter, 9, 101-222.

- Böhmer C, Plateau O, Cornette R, Abourachid A. (2019). Correlated evolution of neck length and leg length in birds. $R$ Soc Open Sci 6: 181588.DOI: $10.1098 /$ rsos.181588

-Böhmer C., Prevoteau J., Duriez O., Abourachid A (2020) Gulper, ripper and scrapper: anatomy of the neck in three species of vultures J Anat 236 (4) :701-723 doi.org/10.1111/joa.13129

- Bout RG (1997) Posture of the avian craniocervical colum J Morphol 231: 287-295

- Cobley MJ, Rayfield EJ, Barrett PM (2013) Inter-Vertebral Flexibility of the Ostrich Neck: Implications for Estimating Sauropod Neck Flexibility. PLOS ONE 8(8): e72187. doi:10.1371/journal.pone.0072187,

- Kambic RE, Biewener AA Pierce SE (2017) Experimental determination of three-dimensional cervical joint mobility in the avian neck Frontiers in Zoology 14:37 DOI 10.1186/s12983-017-0223-z

- Kardong K, V (2012) Vertebrates : comparative anatomy, function, evolution , 6th ed. McGraw-Hill N.Y.794 pp

- Krings M, Nyakatura JA, Boumans ML, Fischer MS, Wagner H. (2017) Barn owls maximize head rotations by a combination of yawing and rolling in functionally diverse regions of the neck. J Anat. 521 231:12-22.

- Krings M, Nyakatura JA, Fischer MS, Wagner H (2014) The Cervical Spine of the American Barn Owl (Tyto furcata pratincola): I. Anatomy of the Vertebrae and Regionalization in Their S-Shaped Arrangement. PLOS ONE 9(3): e91653. doi:10.1371/journal.pone.0091653

- Müller J, Scheyer TM, Head JJ, Barrett PM, Werneburg I, Ericson PGP, Pol D, Sánchez-Villagra MS (2010) Homeotic effects, somitogenesis and the evolution of vertebral numbers in recent and fossil amniotes PNAS 107 (5) :2118-2123; DOI: 10.1073/pnas.0912622107

- Lu J, Ebraheim NA, Huntoon M, Haman SP (2000) Cervical intervertebral disc space narrowing and size of intervertebral foramina. Clinical orthopaedics and related research 370 : 264531 Romer AS, Parsons TS (1977) The vertebrate Body. WB Saunders Co Philadelphia - 624 pp.

- Taylor MP, Wedel MJ (2013) The Effect of Intervertebral Cartilage on Neutral Posture and Range of Motion in the Necks of Sauropod Dinosaurs. PLoSONE 8(10): e78214. doi:10.1371/journal.pone.0078214

-Terray, L., Plateau, O., Abourachid, A. et al. 2020 Modularity of the Neck in Birds (Aves). Evol Biol 2020. doi.org/10.1007/s11692-020-09495-w

- Van der Leew A H J, Bout R, G, Zweers G, A. (2001) Control of the cranio-cervical system during feeding in birds Amer Zool 41 :1352-1363.

- Wang H, Zhou C, Yu Y, Wange C, Tsai T-Y, Han C, Li G, Cha T (2021) Quantifying the ranges of relative motions of the intervertebral discs and facet joints in the normal cervical spine, J Biomechanics 112 542110023 DOI :10.1016/j.jbiomech.2020.110023 
Table 1. Points on the digital model
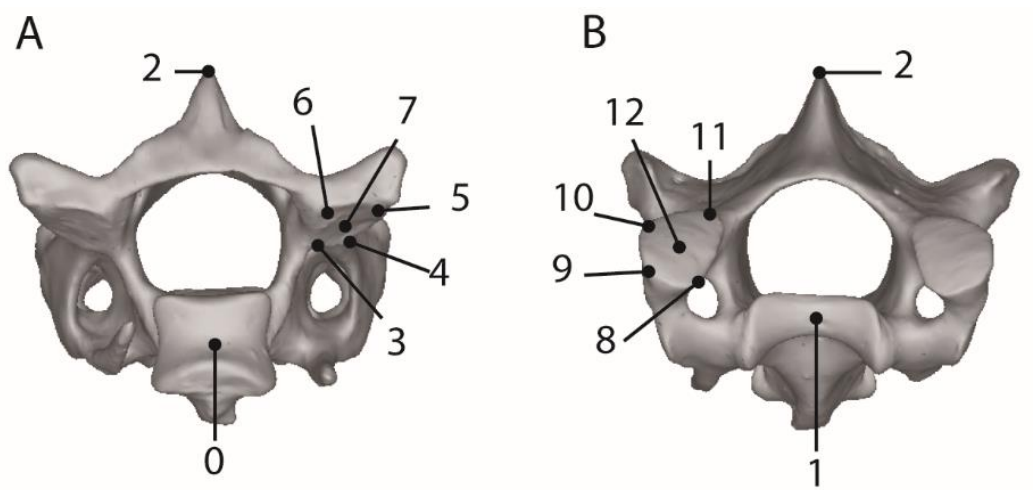

\begin{tabular}{|c|l|}
\hline 0 & caudal articular surface of the vertebral body, geometrical center \\
\hline 1 & cranial articular surface of the vertebral body, geometrical center \\
\hline 2 & neural spine sagittal dorsal-most point \\
\hline 3 & right postzygapophysis, medial caudal-most point \\
\hline 4 & right postzygapophysis, medial cranial-most point \\
\hline 5 & right postzygapophysis, lateral cranial-most point \\
\hline 6 & right postzygapophysis, lateral caudal-most point \\
\hline 7 & right postzygapophysis, geometrical center \\
\hline 8 & right prezygapophysis, medial caudal-most point \\
\hline 9 & right prezygapophysis, medial cranial-most point \\
\hline 10 & right prezygapophysis, lateral cranial-most point \\
\hline 11 & right prezygapophysis, lateral caudal-most point \\
\hline 12 & right prezygapophysis, geometrical center \\
\hline 13 & mediodorsal point of the caudal aspect of the medullar canal \\
\hline
\end{tabular}




\section{Table 2 :Results}

\begin{tabular}{|c|c|c|c|c|c|c|c|c|c|c|c|c|}
\hline \multirow[b]{3}{*}{ Modules } & \multicolumn{6}{|c|}{ Zygapophysis positions } & \multicolumn{4}{|c|}{ Zygapophysis orientations } & \multirow[b]{3}{*}{ joint } & \multirow{3}{*}{ sagittal flexion } \\
\hline & \multicolumn{2}{|c|}{ sagittal } & \multicolumn{2}{|c|}{ frontal } & \multicolumn{2}{|c|}{ transversal } & \multicolumn{2}{|c|}{ sagittal } & \multicolumn{2}{|c|}{ transversal } & & \\
\hline & prezygaP & postzygaP & prezygaP & postzygaP & prezygaP & postzygaP & prezygaP & postzygaP & prezygaP & postzygaP & & \\
\hline 1 & -40 & -12 & -23 & -10 & 62 & 51 & 46 & 19 & -18 & -11 & 1 & -28 \\
\hline 9 & -14 & -13 & -17 & -18 & 40 & 37 & 22 & 13 & -55 & -35 & 9 & -1 \\
\hline 2 & 22 & -3 & 19 & -3 & 50 & 44 & -3 & 9 & -46 & -43 & 2 & 26 \\
\hline 5 & 27 & 22 & 15 & 15 & 63 & 56 & -13 & -7 & -25 & -30 & 5 & 6 \\
\hline 6 & -11 & 3 & -14 & 4 & 39 & 32 & 15 & 9 & -44 & -31 & 6 & -14 \\
\hline 3 & -7 & -4 & -7 & -5 & 44 & 39 & 9 & 13 & -48 & -30 & 3 & -3 \\
\hline 7 & -18 & -23 & -21 & -28 & 40 & 38 & 22 & 24 & -36 & -21 & 7 & 5 \\
\hline 8 & -14 & -13 & -17 & -18 & 40 & 37 & 16 & 18 & -53 & -30 & 8 & -1 \\
\hline \multicolumn{13}{|l|}{ Gyps fulvus } \\
\hline 3 & -34 & -12 & -25 & -12 & 55 & 47 & 48 & 23 & -16 & 1 & $3 / 4$ & -25 \\
\hline 4 & -38 & -5 & -26 & -6 & 57 & 43 & 51 & 20 & -13 & -4 & $4 / 5$ & -26 \\
\hline 5 & -31 & 15 & -25 & 13 & 52 & 49 & 40 & 5 & -20 & -43 & $5 / 6$ & -7 \\
\hline 6 & 8 & 29 & 6 & 23 & 53 & 53 & -2 & -3 & -53 & -57 & $6 / 7$ & 12 \\
\hline 7 & 42 & 20 & 26 & 21 & 62 & 42 & -19 & -3 & -54 & -42 & $7 / 8$ & 12 \\
\hline 8 & 32 & 32 & 21 & 25 & 59 & 53 & -17 & -7 & -58 & -53 & $8 / 9$ & -8 \\
\hline 9 & 24 & -7 & 22 & -11 & 48 & 31 & -8 & 14 & -57 & -15 & $9 / 10$ & -2 \\
\hline 10 & -8 & -13 & -11 & -19 & 36 & 34 & 6 & 11 & -44 & -22 & $10 / 11$ & 5 \\
\hline 11 & -8 & -13 & -11 & -19 & 36 & 34 & 15 & 11 & -41 & -23 & $11 / 12$ & -5 \\
\hline 12 & -18 & -9 & -25 & -14 & 35 & 32 & 24 & 8 & -39 & -19 & $12 / 13$ & -11 \\
\hline 13 & -20 & -7 & -27 & -11 & 35 & 33 & 21 & 11 & -43 & -23 & $13 / 14$ & -15 \\
\hline 14 & -22 & -5 & -30 & -8 & 35 & 32 & 24 & 8 & -40 & -20 & $14 / 15$ & -17 \\
\hline 15 & -22 & -7 & -30 & -12 & 34 & 30 & 22 & 11 & -37 & -21 & & \\
\hline \multicolumn{13}{|c|}{ Hirundo rustica } \\
\hline 3 & -32 & -19 & -17 & -11 & 64 & 61 & 38 & 17 & -27 & 1 & $3 / 4$ & -31 \\
\hline 4 & -50 & -1 & -23 & 0 & 70 & 58 & 37 & 13 & -20 & -8 & $4 / 5$ & -6 \\
\hline 5 & -7 & 36 & -4 & 18 & 60 & 66 & -15 & 11 & -9 & -51 & $5 / 6$ & 13 \\
\hline 6 & 49 & 47 & 22 & 22 & 71 & 69 & -30 & -21 & -52 & -39 & $6 / 7$ & 5 \\
\hline 7 & 52 & 15 & 22 & 9 & 73 & 59 & -30 & -3 & -40 & -38 & $7 / 8$ & 19 \\
\hline 8 & 34 & -7 & 20 & -6 & 62 & 49 & -12 & 14 & -60 & -31 & $8 / 9$ & 17 \\
\hline 9 & 10 & -8 & 8 & -8 & 50 & 46 & 0 & 17 & -48 & -32 & $9 / 10$ & 3 \\
\hline 10 & -5 & -11 & -5 & -12 & 48 & 42 & 10 & 22 & -43 & -26 & $10 / 11$ & 6 \\
\hline 11 & -5 & -11 & -5 & -12 & 48 & 42 & 15 & 23 & -40 & -40 & $11 / 12$ & -1 \\
\hline 12 & -12 & -12 & -14 & -14 & 41 & 39 & 15 & 15 & -49 & -48 & $12 / 13$ & -4 \\
\hline
\end{tabular}


SM figure : points digitalized on the vertebra

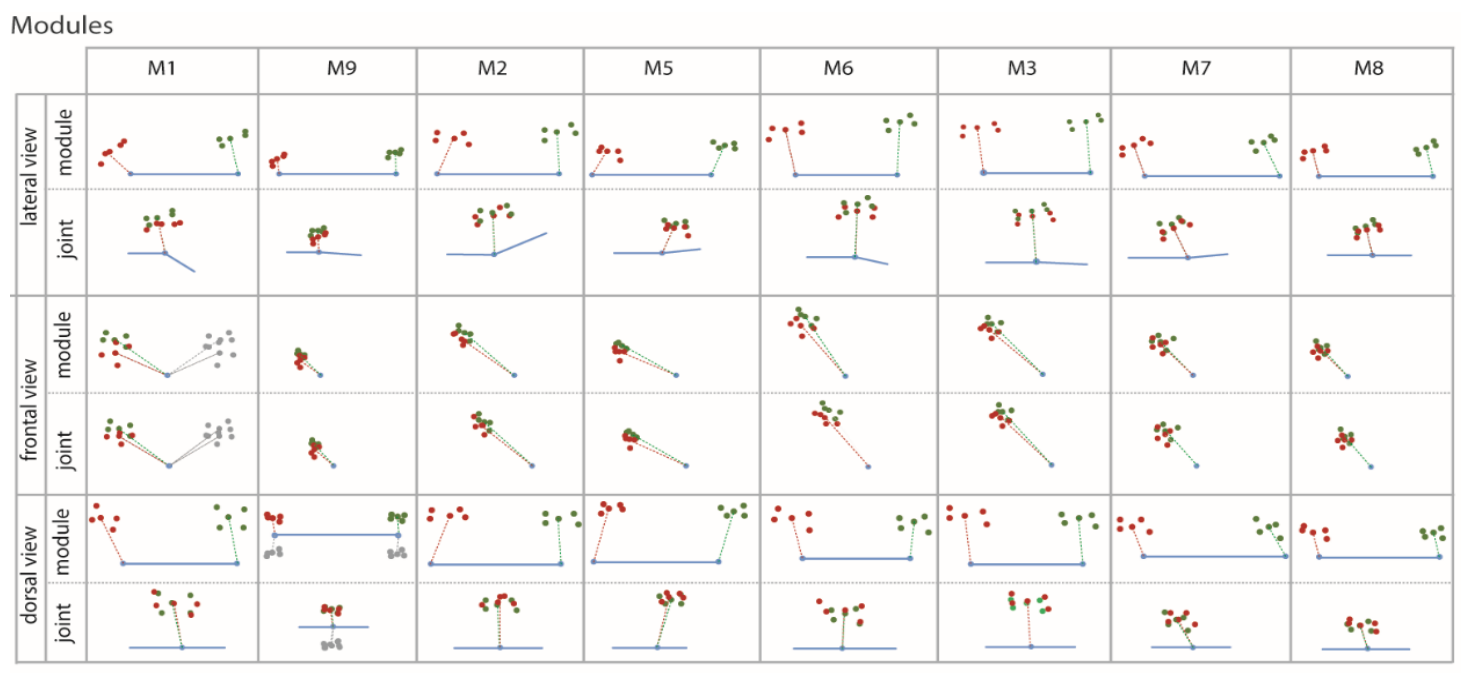

Gyps fulvus

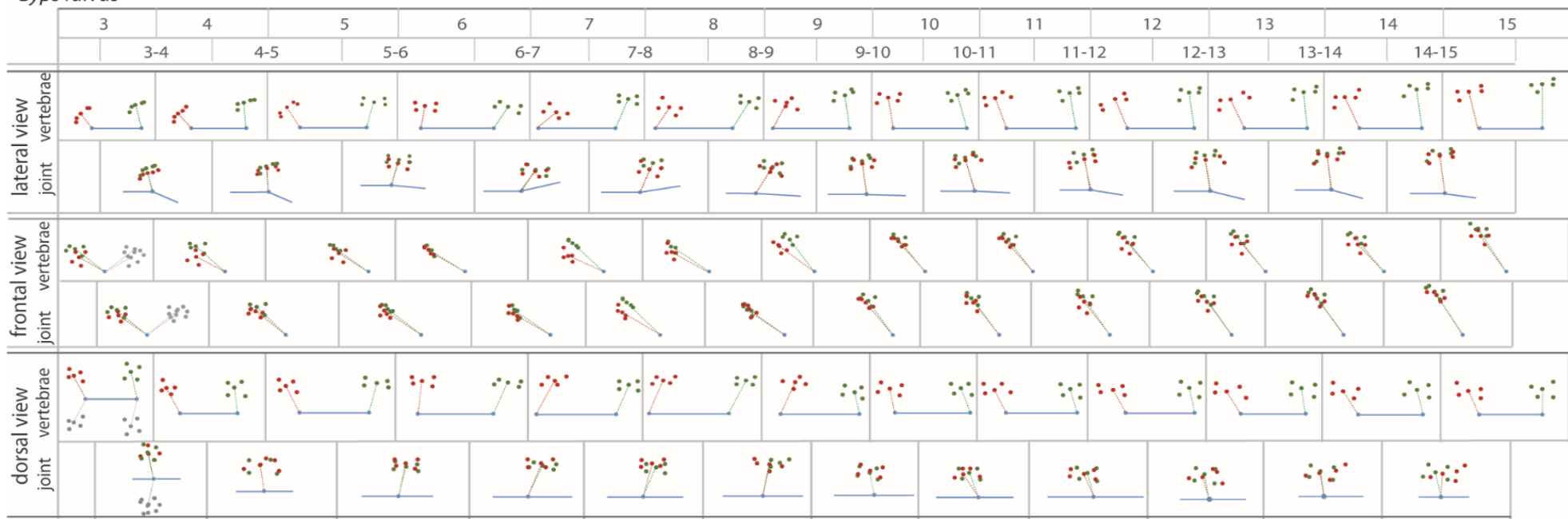

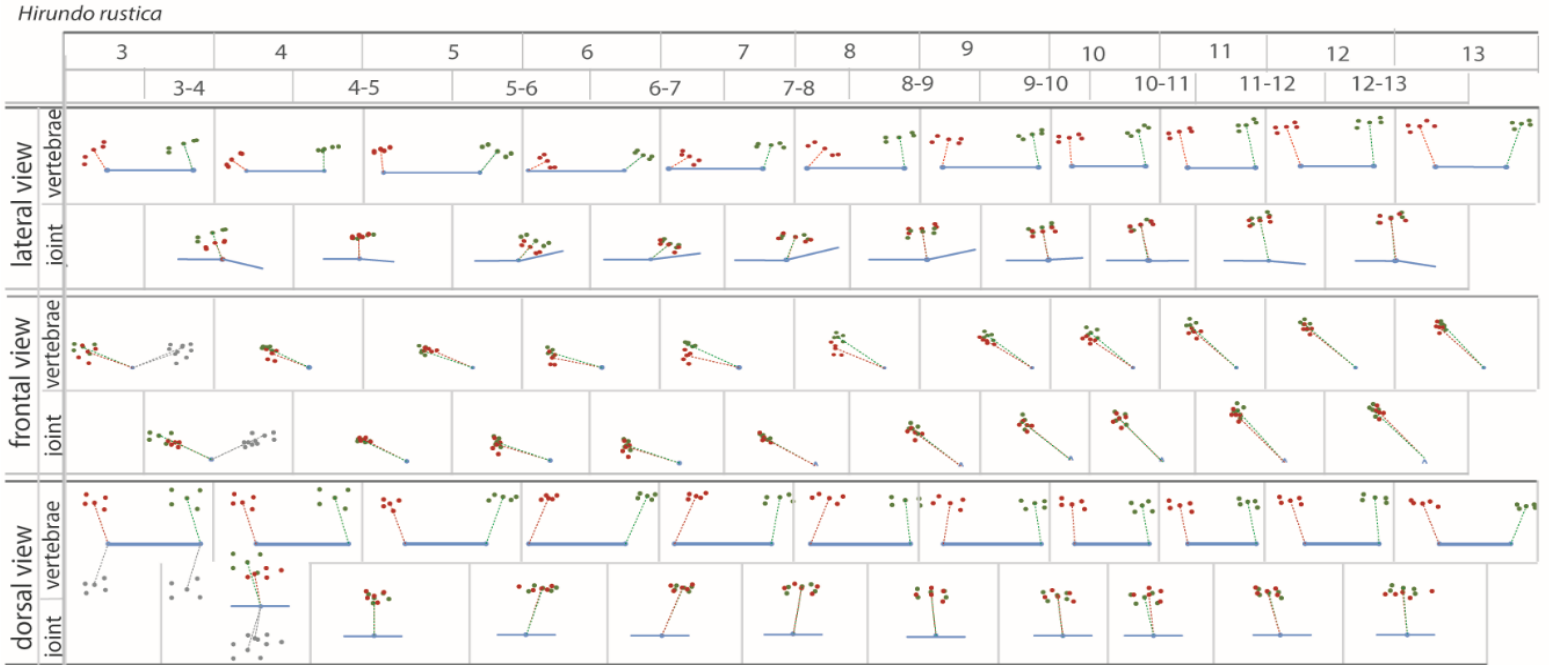

Red dots : points on the prezygapophyses- Green dots: points on the postzygapophyses- Blue dots: points on the centrum - Blue line: centrum. On the frontal and dorsal views, only one side is presented except for the first joint. 